\title{
Investigating the Role of Interaction, Attitudes, and Intentions for Enroll- ment and Persistence in Engineering among Underrepresented Minority Stu- dents
}

\section{Dr. Sandra Loree Dika, University of North Carolina, Charlotte}

Dr. Sandra Dika is Assistant Professor of research methods in the Department of Educational Leadership at UNC Charlotte. Her current research is focused on college access and success for underrepresented and underserved student groups in higher education.

\section{Dr. Miguel A. Pando, University of North Carolina, Charlotte}

Dr. Miguel A. Pando is currently an Associate Professor of Civil and Environmental Engineering at the University of North Carolina at Charlotte (UNCC), and was previously an Associate Professor of Civil Engineering at the University of Puerto Rico at Mayaguez (UPRM). In addition to his research in Geotechnical Engineering on the topics of soil-structure interaction and engineering characterization of geomaterials, Dr. Pando has been actively involved in teaching and mentoring students at both UPRM and UNCC, including 14 undergraduate civil engineering students through the NSF Louis Stokes Alliance for Minority Participation Program. Examples of his recent and ongoing engineering education research projects include the development of a Bridge to the Doctoral Program to attract Latinos to geotechnical earthquake engineering (NSF-NEES), use of a multi-institutional classroom learning environment for remote geotechnical engineering education (NSF-TUES), as well as a mixed methods study of the role of student-faculty relationships in the persistence and retention of underrepresented minority students in engineering (NSF-RIGEE). For the past few years, he has co-led the "Engineering for Development Workers" summer study abroad course at UNCC, focused on undertaking Civil Engineering projects in rural communities in Andean Peru.

\section{Dr. Brett Tempest, University of North Carolina, Charlotte}

Brett Quentin Tempest is an Assistant Professor of civil and environmental engineering at University of North Carolina, Charlotte. His primary research area is in construction materials with special emphasis on concretes and incorporation of wastes and combustion residues in high performance structural materials. Tempest advises the International Service Club in the College of Engineering and recently returned from the group's first overseas trip to Peru. 


\title{
Investigating the Role of Interaction, Attitudes, and Intentions for Enrollment and Persistence in Engineering among Underrepresented Minority Students
}

\begin{abstract}
One of the most significant challenges facing engineering education in the United States is the persistent problem of inclusion and retention of certain racial and ethnic groups - particularly blacks and Latinos. This paper, part of the NSF Awardees Poster Session, presents results from a RIGEE-funded project whose aim is study how formal and informal interactions with engineering agents (professionals and faculty) influence attitudes and intentions of underrepresented minority (URM) students for enrollment and persistence in engineering. The project employs a case study approach focused on two key phases of engineering education initial enrollment and persistence to advanced program stages - guided by a framework that incorporates social cognitive, social capital, and community cultural wealth theories. We report on the findings of four studies conducted as part of this project, which guide recommendations for further research and practice.
\end{abstract}

\section{Introduction}

The participation of women and underrepresented minorities in engineering has been "disturbingly slow" [1]. To address the chronic issues of underrepresentation in engineering education, a small but growing body of research has attempted to move away from a deficit perspective and has examined social and cultural explanations for engineering persistence among women, racial/ethnic minorities, first-generation college students, and other underrepresented groups. Frameworks emphasizing social and cultural capital; as well as the unique forms of capital possessed by students from marginalized groups (e.g., cultural wealth); offer alternate perspectives to focus on how underrepresented students navigate and persist in engineering.

As part of a federally funded project on the role of student-faculty interaction for the persistence of underrepresented racial/ethnic minority (URM) students in engineering, we have collected mixed methods data from undergraduate engineering students at one college of engineering in a Predominantly White urban research university in the Southeastern US. We obtained quantitative data using questionnaires from both "new entrants" (first-year) and "persisters" (junior and senior) in engineering. Our qualitative data collection (interviews and focus groups) focused specifically on two underrepresented racial/ethnic groups in engineering - black and Latino students. In this paper, we summarize the bodies of literature guiding the project, outline the project methodology, summarize the results of four studies, and offer some preliminary recommendations for research and practice based on these findings.

Participation and persistence in engineering for underrepresented students

Differing participation and persistence in engineering has been investigated using theoretical frameworks from higher education ${ }^{[2,3]}$, sociology ${ }^{[4,5,6]}$, and psychology ${ }^{[7]}$. The importance of interactions, resources, and supports is prominent across these theories, as precursors to beliefs about one's abilities and identity that support academic effort, performance, and career 
persistence. Research and theory on interactions with faculty, other sources of capital (i.e., cultural wealth), and self-efficacy, particularly for underrepresented students in engineering, frames this study.

Interactions with faculty

Predominant frameworks of participation and persistence in higher education emphasize the role of student interaction with faculty ${ }^{[2,3]}$. Social capital frameworks offer another way to understand how and why interaction with faculty is important for persistence of students in STEM, through defining ties to institutional agents (faculty, staff, administrators) as links to important information needed to navigate and succeed in the college environment ${ }^{[8-12]}$. Studentfaculty interactions (SFI) are vital to the success of all engineering students, but especially underrepresented racial/ethnic minority groups (URM). Research over the past 15 years has evidenced the relationship of SFI with academic performance, persistence, and academic and personal growth for URM students in STEM disciplines, including engineering.

Academic performance: Underrepresented students of color (i.e., black, Latino, Native American) in STEM disciplines benefit greatly from faculty-student interactions. Frequent interactions with faculty and support from contact with faculty are linked with higher grades ${ }^{[13,14]}$. Additionally, faculty mentorship may lead to higher academic performance even if students had low testing performance prior to college ${ }^{[15]}$. The nature of interaction with faculty may also be important. While interactions related to course materials may not relate to higher GPA $^{[14]}$, conducting research with faculty members is associated with improvements in academic performance ${ }^{[16,17]}$. Faculty-student interactions are generally beneficial to URM students especially when conducting research with faculty or receiving mentorship from faculty, however some literature suggests that receiving criticism from faculty or interacting with faculty to discuss course materials did not suggest that students would increase their GPAs.

Persistence: The academic persistence of engineering students is higher than students in other majors ${ }^{[18]}$ yet research unfailingly reveals that black and Latino engineering students are underrepresented and have lower persistence rates than their White peers. Additionally, the literature has found that black and Latino students may resist initiating contact with predominantly white faculty out of fear of being stereotyped or negatively perceived by faculty and prefer same-race faculty mentors ${ }^{[19,20,21]}$. Conversely, authors in one study found that interactions outside of ethnicity with faculty and peers were beneficial and increased underrerpresented students' confidence ${ }^{[22]}$. Overall, engineering students' interactions with faculty are vital for retention and persistence ${ }^{[23,24,25]}$ and are especially critical for black and Latino students in ensuring their academic success ${ }^{[8,14,26,27]}$.

Academic \& personal growth: There are several benefits of faculty-student interactions for URM students in engineering including increased development in intellectual and personal growth while at higher education institutions. Students' interactions with faculty can provide high levels of satisfaction in intellectual ability, problem solving, career development, and scientific reasoning ${ }^{[28,29]}$. However, problem solving and intellectual growth are especially increased for students of color ${ }^{[28]}$. More frequent contact with faculty has also been linked to self-efficacy among engineering students ${ }^{[23,25]}$. 
URM engineering students' interactions with faculty members are important for developing intellectual thinking and growth because more exposure to knowledge and resources build students' abilities to perform tasks in while and out of the classroom. Personal and intellectual growth for black and Latino students in engineering increases when interacting with faculty because students are able to critically think when engaged with various research and engineering-related projects (as assigned by faculty) and gain more exposure and knowledge than they previously had. However, research shows that URM engineering and STEM students may have frequent interactions with faculty, but feel less satisfied with those interactions since they are less meaningful and are less likely to engage in undergraduate research with faculty members ${ }^{[21,26,30]}$.

Cultural wealth as capital for engineering

Traditional social and cultural capital theories ${ }^{[4,5]}$ emphasize how the values and practices of dominant groups are rewarded in education. The notion of community cultural wealth $(\mathrm{CCW})^{[31]}$ was developed to show how communities of color and other non-dominant groups create wealth that is valuable for persisting in education. Yosso ${ }^{[31]}$ delineates six forms of CCW:

1) Aspirational capital: The ability to maintain hopes and dreams for the future, considering real and perceived barriers.

2) Linguistic capital: The ability to switch communication styles or languages based on environment (e.g., academic and nonacademic).

3) Familial capital: Knowledge gained from, and maintenance of a connection to the home community and culture.

4) Social capital: Networks of people and resources that provide instrumental and emotional support to navigate through institutions.

5) Navigational capital: Skills of navigating through social institutions that are designed for dominant social and cultural groups.

6) Resistant capital: Knowledge and skills developed through oppositional behavior that challenges inequality.

The notion of CCW as an alternative framework to understand the success of URM and other underrepresented groups (e.g., first-generation and students from low-income families) in engineering has yet to be explored in-depth. A recent dissertation study; conducted as part of our project; demonstrates this promise and reveals how black and Latino engineering students are empowered by different forms of capital related to their background, culture, and experiences [32].

Engineering self-efficacy

Previous research on the role of self-efficacy beliefs in engineering support the notion that they are strong predictors of academic achievement and engineering interest ${ }^{[33,34]}$. Self-efficacy figures prominently in Social-Cognitive Career Theory (SCCT) ${ }^{[7]}$ to explain achievement and career-related choices. The authors of the theory suggest that contextual factors are particularly influential for underrepresented groups, and have successfully employed the theory to understand 
engineering interest and goals ${ }^{[35,36,37]}$, adjustment ${ }^{[38]}$, satisfaction ${ }^{[39]}$, and persistence ${ }^{[40]}$ among college engineering students. Other researchers have employed the framework to understand persistence of ethnic minority women in engineering ${ }^{[41,42]}$.

Marra and colleagues ${ }^{[43]}$ developed the Longitudinal Assessment of Engineering Self-Efficacy (LAESE) to measure self-efficacy, feelings of inclusion, and outcome expectations of women studying engineering. This instrument was further revised by Concannon and Barrow ${ }^{[44]}$ to include four subscales -engineering self-efficacy I and II (ESE I and II), coping self-efficacy (CSE), and engineering career outcome expectations (ECOE). These authors found effects of gender for CSE (women lower than men) and ECOE (women higher than men) ${ }^{[45]}$. These studies considered ethnicity and transfer status, but not relationships with engineering faculty and other forms of capital that influence self-efficacy and outcome expectations.

Project methodology

As part of the two-year project, we administered questionnaires and conducted interviews and focus groups with first-year (new entrants) and junior and senior (persisters) engineering students at one college of engineering in a Predominantly White urban research university in the Southeastern US. Questionnaires were open to all engineering students, while focus groups were open to only students who identified as black and/or Latino. The college of engineering at this institution enrolls over 2,500 students in programs in seven different undergraduate engineering programs. Black and Latino students make up small proportions of the overall engineering population ( $7 \%$ Black, $6 \%$ Latino), whose distribution varies significantly by engineering degree program. Women engineering students of color make up much higher proportions among their race/ethnicity groups $(14 \%-15 \%)$ than their White counterparts $(8 \%)$.

Instrumentation and data collection

Questionnaire for new entrants: The questionnaire items were developed by adapting existing instruments on perceived barriers to education ${ }^{[46]}$ and engineering-related interactions ${ }^{[41]}$. The items were included on a standard questionnaire administered electronically to the engineering first-year seminar students at the institution under study during the first week of classes. Seven items on likelihood to experience certain barriers (e.g., negative faculty attitudes, coursework difficulties) were rated from $1=$ strongly agree to $5=$ strongly disagree. For seven items on precollege engineering-related interactions (e.g., visiting an engineering workplace), students indicate all of the adults with whom they interacted from five possible options: parent, family friend, K-12 educator, college professor, or other adult mentor. Item scores were created to indicate the number of adults providing each type of interaction support (range 0 to 5). Additional demographic questions included whether the student's parent had attained a four-year degree, to determine first-generation status. Gender and race/ethnicity were obtained as reported in the institution's student records database. A total of 252 new entrants participated in the questionnaire, with the majority identifying as white/Caucasian (80\%) and $11 \%$ from underrepresented groups (4\% black, $7 \%$ Latino).

Focus group protocol for black and Latino new entrants: The focus group protocol included questions prompting discussion about support and encouragement received from family, 
educators, and other mentors during middle and high school; expectations about interacting with professors on first day of classes; interactions with engineering professors; factors that affect how students and professors interact and in and outside of the classroom; relationship they would like to have with professors; importance of interaction with professors to help motivate continuing in engineering studies; and aspects of student-faculty interaction that are unique to engineering. Two focus group interviews were conducted in an on-campus student residence building where the engineering learning community is located during October-November 2013. Six students participated, all male and equally divided by racial/ethnic identification ( 3 black, 3 Latino). Interviews were digitally recorded and transcribed verbatim.

Questionnaire for persisters: We developed an online questionnaire for persisters in engineering including items on support and interactions prior to enrolling in engineering ${ }^{[41]}$ ( 7 items), frequency of out-of-class interactions with faculty (4 items), assessment of quality of relationships with faculty, students, and staff (6 items), barriers experienced during studies ${ }^{[46]}$ (7 items), engineering self-efficacy (17 items), and cultural wealth (9 items). A total of 275 students participated in the questionnaire, with the majority identifying as white/Caucasian (74\%) and male $(80 \%)$. About $17 \%$ of respondents indicating belonging to one of the two underrepresented racial/ethnic groups ( $9 \%$ black, $8 \%$ Latino).

While research to study the concept of cultural wealth has generally utilized qualitative methods, we developed nine items for our questionnaire to explore whether and how the different forms of capital could be assessed quantitatively. Social capital was divided into 4 items to assess different networks and resources (peers, faculty/staff, campus organizations, off-campus organizations). The wording of the statements was developed using the descriptions in Yosso ${ }^{[31]}$, and students indicated a level of agreement with each statement from $1=$ strongly disagree to $5=$ strongly agree. Seventeen items related to engineering self-efficacy were utilized from an existing instrument ${ }^{[44,45]}$, which respondents rated on a 7-point scale from $1=$ strongly disagree to $7=$ strongly agree, as in the original instrument.

Focus group protocol for black and Latino persisters: The interview protocol for black and Latino persisters included questions prompting discussion about support and encouragement received from family, educators, and other mentors during middle and high school; interactions with engineering professors; aspects of student-faculty interaction that are unique to engineering and factors that affect how students and professors interact; and the relative importance of their relationships with professors in motivating their persistence in engineering. Four focus group interviews were conducted on the campus in one of the main engineering buildings during the 2014-15 academic year. Interviews were conducted in the later afternoon/evening, and we provided a casual dinner (pizza or sandwiches). Two of the focus groups included both black and Latino students, while the other two interviews were conducted through student chapters of NSBE (Black students) and SHPE (Latino students). Participants were 6 women (3 Black, 3 Latina), and 12 men (7 Black, 5 Latino). Interviews were digitally recorded and transcribed verbatim.

Brief summary of findings 
Differences in pre-college interactions, early expectations, and perceived barriers for engineering students from underrepresented groups

In this exploratory quantitative study ${ }^{[47]}$, we looked at data from the new entrants' questionnaire to investigate how engineering-related interactions prior to college, perceived barriers during engineering studies, and early expectations of interactions with faculty may differ among engineering students related to membership in an underrepresented group. By conducting pairwise comparisons based on gender, parental education, and race/ethnicity, membership in an underrepresented group was associated with significantly greater perceived likelihood of financial barriers (women, first-generation), lack of support from family (first-generation, students of color) and negative attitudes from faculty (first-generation). There were no significant differences in perceived likelihood to experience problems with coursework or fitting in with peers.

Engineering-related interactions, perceived barriers, and early expectations of black and Latino new entrants to engineering

In this case study of black and Latino students entering into engineering ${ }^{[48]}$, we explored the question: What are the engineering-related interactions prior to college, perceived barriers during engineering studies, and early expectations of interactions with faculty for first year black and Latino engineering students? Sources of data included the questionnaire responses for 11 Black students (6 men, 5 women) and 18 Latino students (16 men, 2 women) and the six male focus group participants. Analysis of these data revealed three important themes: pre-college interactions with educators (particularly calculus teachers); limited early interactions with engineering faculty; factors that affect student-faculty interaction and faculty perceptions of students; desire and expectations for faculty to provide links to opportunities; and unique factors and barriers related to the nature and culture of engineering.

Forms of capital and self-efficacy for black and Latino persisters

In this exploratory quantitative study of black and Latino persisters (junior and senior) in engineering ${ }^{[49]}$, we focused on understanding how perceived relations with faculty and other forms of capital from the CCW framework are related to engineering self-efficacy. The data source for the study was the responses from 41 students from underrepresented groups on the persisters questionnaire (24 Black and 17 Latino). Descriptive quantitative data indicate that persisters view their relationships with engineering faculty as positive and supportive, and they employ several types of capital, particularly aspirational capital (ability to maintain hopes and dreams for the future) and linguistic capital (having the ability to switch communication styles or language). All sources of capital (relationships with faculty and the six $\mathrm{CCW}$ forms) were positively related to engineering self-efficacy, with most correlations being statistically significant. Notably strong correlations were found between engineering self-efficacy and four forms of capital: aspirational, familial, social capital-peers, and social capital-faculty.

How students of color draw on forms of capital to successfully persist in engineering 
The purpose of this case study ${ }^{[50]}$ was to describe how engineering persisters of color use different forms of cultural wealth ${ }^{[31]}$ to achieve their goal of obtaining an engineering degree. Data from the persisters questionnaire (24 black and 17 Latino students) and from the persisters focus groups (10 black, 8 Latino) were examined by the researchers. Descriptive quantitative data indicate that persisters employ several types of capital, with aspirational, linguistic, familial, and peer social capital being the most prevalent. Focus group discussions revealed how persisters remain focused on their goal to become engineers despite barriers and challenges, use family as a source of support and motivation, and find support from faculty in the competitive culture of engineering.

Project summary and implications

The findings from the multiple studies conducted as part of this project point to the importance of both pre-college and college experiences and interactions, as well as multiple forms of capital in the persistence of black and Latino students in engineering. While the results provide snapshots at entry and advanced participation rather than longitudinal data, taken together they tell a compelling story about successful trajectories of engineering education for underrepresented students.

The findings of this project have implications for educational practice and policy. At the institutional level, educational personnel should be aware that while general support and encouragement is important, underrepresented students will benefit most from interactions that connect them to enriching educational experiences that are required for employment and graduate study in engineering.

- Institutional resources and supports: Administrative personnel should promote and provide resources for physical spaces and experiences where students can interact with faculty more effectively to access these supports and information, rather than simply encouraging faculty to interact more with students (or vice versa).

- Centrality of undergraduate research: Resources for undergraduate research - for both students and faculty - are key to fostering interactions that are mutually beneficial. Several programs of the National Science Foundation (e.g., Louis Stokes Alliance for Minority Participation [LSAMP]) support institutions to increase number of URM in STEM disciplines, and these funds should be used to transform institutional capacity.

- Responsive advising: In many institutions, academic advising for engineering is primarily done by advising professionals (not engineering faculty). In these cases, there must be seamless processes for the flow of information about opportunities. Additionally, institutions should require professional development in cultural competencies for faculty and advising staff.

\section{References}

[1] National Science Foundation (NSF), National Center for Science and Engineering Statistics. (2013). Women, minorities, and persons with disabilities in science and engineering: 2013 (Special Report NSF 13304). Arlington, VA: Author. Retrieved from http://www.nsf.gov/statistics/wmpd/

[2] Astin, A. W. (1993). What matters in college? Four critical years revisited. San Francisco: Jossey-Bass. 
[3] Tinto, V. (1993). Leaving college: Rethinking the causes and cures of student attrition (2nd ed.). Chicago, IL: University of Chicago Press.

[4] Coleman, J. S. (1988). Social capital in the creation of human capital. American Journal of Sociology, 94, (Supplement: Organizations and Institutions: Sociological and Economic Approaches to the Analysis of Social Structure), S95-S120.

[5] Bourdieu, P. (1986). The forms of capital. In J. G. Richardson (Ed.), Handbook of Theory and Research for the Sociology of Education (pp. 241-258). Westport, CT: Greenwood Press.

[6] Lin, N. (2001). Social capital: A theory of social structure in action. New York: Cambridge University Press.

[7] Lent, R.W., Brown, S.D., \& Hackett, G. (1994). Toward a unifying social-cognitive theory of career and academic interest, choice, and performance, Journal of Vocational Behavior, 45, 79-122.

[8] Martin, J. P., Simmons, D. R., \& Yu, S. L. (2013). The role of social capital in the experiences of Hispanic women engineering majors. Journal of Engineering Education, 102, 227-243.

[9] Martin, J. P., Miller, M. K., \& Simmons, D. R. (2014). Exploring the theoretical social capital "deficit" of first generation college students: Implications for engineering education. International Journal of Engineering Education, 30(4), 822-836.

[10] Martin, J. P., Simmons, D. R., \& Yu, S. L. (2014). Family roles in engineering undergraduates' academic and career choices: Does parental education attainment matter? International Journal of Engineering Education, 30(1), 136-149.

[11] Stanton-Salazar, R. (1997). A social capital framework for understanding the socialization of racial minority children and youth. Harvard Educational Review, 67(1), 1-40.

[12] Stanton-Salazar, R. D. (2001). Manufacturing hope and despair: The school and kin support networks of U.S.-Mexican youth. New York, NY: Teachers College.

[13] Cole, D. (2008). Constructive criticism: The role of student-faculty interactions on African American and Hispanic students' educational gains. Journal of College Student Development, 49(6), 587-605. doi:10.1353/csd.0.0040

[14] Cole, D., \& Espinoza, A. (2008). Examining the academic success of Latino students in science technology engineering and mathematics (STEM) majors. Journal of College Student Development, 49(4), 285-300. doi: $10.1353 /$ csd. 0.0018

[15] Carini, R., Kuh, G., \& Klein, S. (2006). Student engagement and student learning: Testing the linkages. Research in Higher Education, 47(1), 1-32.

[16] Barlow, A. E. L., \& Villarejo, M. (2004). Making a difference for minorities: Evaluation of an educational enrichment program. Journal of Research in Science Teaching, 41(9), 861-881.

[17] Kim, Y. K., \& Sax, L. J. (2009). Student-faculty interaction in research universities: Differences by student gender, race, social class, and first- generation status. Research in Higher Education, 50, 437-459.

[18] Ohland, M. W., Sheppard, S. D., Lichtenstein, G., Eris, O., Chachra, D., \& Layton, R. A. (2008). Persistence, engagement, and migration in engineering. Journal of Engineering Education, 97(3), 259-278. doi:10.1002/j.2168-9830.2008.tb00978x

[19] Noel, R. C., \& Smith, S. E. (1996). Self-disclosure of college students to faculty: The influence of ethnicity. Journal of College Student Development, 37 (1), 88-94.

[20] Schwitzer, A. M., Griffin, O. T., Ancis, J. R., \& Thomas, C. (1999). Social adjustment experiences of African American college students. Journal of Counseling and Development, 77, 189-197.

[21] Hurtado, S., Cabrera, N. L., Lin, M. H., Arellano, L., \& Espinosa, L. L. (2009). Diversifying science: Underrepresented student experiences in structured research programs. Research in Higher Education, 50(2), 189-214.

[22] Byars-Winston, A., Estrada, Y., Howard, C., Davis, D., \& Zalapa, J. (2010). Influence of social cognitive and ethnic variables on academic goals of underrepresented students in science and engineering: A multiple-groups analysis. Journal of Counseling Psychology, 57(2), 205-218.

[23] Amelink, M., \& Meszaros, P. (2011). A comparison of educational factors promoting or discouraging the intent to remain in engineering by gender. European Journal of Engineering Education, 36(1), 47-62.

[24] French, B. F., Immekus, J. C., \& Oakes, W. C. (2005). An examination of indicators of engineering students' success and persistence. Journal of Engineering Education, 94(4), 419-25.

[25] Vogt, C. M. (2008). Faculty as a critical juncture in student retention and performance in engineering programs. Journal of Engineering Education, 97(1), 27-36. 
[26] Cole, D., \& Griffin, K. A. (2013). Advancing the study of student-faculty interaction: A focus on diverse students and faculty. In M. B. Paulsen \& J. C. Smart (Eds.), Higher education: Handbook of theory and research. Springer.

[27] Hurtado, S., Eagan, M. K., Tran, M., Newman, C., Chang, M. J., \& Velasco, P. (2011). "We do science here": Underrepresented students' interactions with faculty in different college contexts. Journal of Social Issues, 67(3), 553-579.

[28] Eimers, M. T. (2001). The impact of student experiences on progress in college: An examination of minority and nonminority differences. NASPA Journal, 38(3), 386-409.

[29] Pascarella, E. T., \& Terenzini, P. T. (2005). How college affects students: A third decade of research. San Francisco: Jossey-Bass.

[30] Williamson, S.Y. (2010). Within-group ethnic differences of Black male STEM majors and factors affecting their persistence in college. Journal of International and Global Studies, 1(2), 45-73.

[31] Yosso, T. J. (2005). Whose culture has capital? A critical race theory discussion of community cultural wealth. Race, Ethnicity and Education, 8, 69-91.

[32] Foxx, K. A. (2014). A cultural wealth perspective on success and persistence in engineering for black and Latino students: Exploring interactions with faculty and other institutional agents (Doctoral dissertation). Retrieved from ProQuest Dissertations and Theses database.

[33] Britner, S. L., \& Pajares, F. (2006). Sources of science self-efficacy beliefs of middle school students. Journal of Research in Science Teaching, 43, 485-499. doi: 10.1002/tea.20131

[34] Mau, W.-C. (2003). Factors that influence persistence in science and engineering career aspirations. The Career Development Quarterly, 51, 3, pp. 234-243.

[35] Lent, R. W., Brown, S. D., Sheu, H., Schmidt, J., Brenner, B. R., Gloster, C. S., ...Treistman, D. (2005). Social cognitive predictors of academic interests and goals in engineering: Utility for women and students at Historically Black Universities. Journal of Counseling Psychology, 52(1), 84-92. doi: 10.1037/00220167.52.1.84

[36] Lent, R. W., Sheu, H-B., Singley, D., Schmidt, J. A., \& Schmidt, L., \& Gloster, C. S. (2008). Longitudinal relations of self-efficacy to outcome expectations, interests, and major choice goals in engineering students. Journal of Vocational Behavior, 73(2), 328-335.

[37] Lent, R. W., Sheu, H-B., Gloster, C. S., \& Wilkins, G. (2010). Longitudinal test of the social cognitive model of choice in engineering students at Historically Black Universities. Journal of Vocational Behavior, 76(3), 387-394.

[38] Lent, R. W., Miller, M. J., Smith, P. E., Watford, B. A., Lim, R. H., Hui, K., et al. (2013). Social cognitive predictors of adjustment to engineering majors across gender and race/ethnicity. Journal of Vocational Behavior, 83(1), 22-30.

[39] Lent, R. W., Singley, D., Sheu, H-B., Schmidt, J. A., \& Schmidt, L. (2007). Relation of social-cognitive factors to academic satisfaction in engineering students. Journal of Career Assessment, 15(1), 87-97.

[40] Lent, R. W., Brown, S. D., Schmidt, J., Brenner, B., Lyons, H., \& Treistman, D. (2003). Relation of contextual supports and barriers to choice behavior in engineering majors: Test of alternative social cognitive models. Journal of Counseling Psychology, 50(4), 458-465. doi:10.1037/0022-0167.50.4.458

[41] Martin., J. P., Yu, S.L., Sha T.-L., Waight, C.L. \& Zerda. K.S (2007). Investigating the relations of ethnicity to female students' perceptions and intention to major in engineering using social cognitive theory. Proceedings of the 37th ASEE/IEEE Frontiers in Education Conference, October 10 - 13, 2007, Milwaukee, WI, pp. T1H7-T1H13.

[42] Trenor, J. M., Yu, S. L., Waight, C. L., Zerda, K. S., \& Sha, T.-L. (2008). The relations of ethnicity to female engineering students' educational experiences and college and career plans in an ethnically diverse learning environment. Journal of Engineering Education, 97(4), 449-465.

[43] Marra, R.M., Rodgers, K.A., Shen, D. \& Bogue, B. (2009). Women engineering students and self-efficacy: A multi-year, multi-institution study of women engineering student self-efficacy. Journal of Engineering Education, 27-38.

[44] Concannon, J. P., \& Barrow, L. H. (2009). A cross-sectional study of engineering students' self-efficacy by gender, ethnicity, year, and transfer status. Journal of Science Education and Technology, 18, 163-172.

[45] Concannon, J. P., \& Barrow, L. H. (2012). A reanalysis of engineering majors' self-efficacy beliefs. Journal of Science Education and Technology, 21, 742-753.

[46] McWhirter, E. H., Hackett, G., \& Bandalos, D. L. (1998). A causal model of the educational plans and career expectations of Mexican American high school girls. Journal of Counseling Psychology, 45(2), 166181. 
[47] Dika, S. L., Pando, M. A., Tempest, B. Q. (2014). Pre-college interactions, early expectations, and perceived barriers: Are there differences for underrepresented engineering students? Proceedings of the 2014 American Society of Engineering Education conference, Indianapolis, IN, June 15-18, 2014 (Paper 10893).

[48] Dika, S. L., Pando, M. A., Tempest, B. Q., \& Foxx, K. A. (2014). Pre-college interactions, early expectations, and perceived barriers of first year Black and Latino engineering students. Proceedings of the 2014 IEEE Frontiers in Education conference, Madrid, Spain, October 22-25, 2014 (http://fieconference.org/)

[49] Dika, S. L., Pando, M. A., Tempest, B. Q., Foxx, K. A., \& Allen, M. E. (2015). Engineering self-efficacy, interactions with faculty, and other forms of capital for underrepresented engineering students. Proceedings of the 2015 Frontiers in Education conference, El Paso, TX, October 21-24, 2015 (http://fieconference.org/).

[50] Dika, S. L., Pando, M. A., Tempest, B. Q., \& Allen, M. E. (2015). Examining how students of color draw on aspirational, familial, and social capital to successfully persist in engineering. Paper presentation at the annual Association for the Study of Higher Education Conference - Council on Ethnic Participation, Denver, CO, November 4-5, 2015. 